\title{
1. Introduction: working with paradata, marginalia and fieldnotes
}

\author{
John Goodwin, Henrietta O'Connor, \\ Ann Phoenix and Rosalind Edwards
}

\section{INTRODUCTION}

While research areas do not just 'appear', the genesis of academic interests and specialities is neither straightforward nor always clear. How we come to be interested in specific areas is often tied up with individual research histories, career trajectories or even chance discoveries and accidental encounters. It may also be the case that while we may think we are working in niche or even obscure fields of enquiry sometimes serendipitous meetings, conversations or exchanges reveal shared interests, common ground and opportunities for future productive collaborations. Indeed, this volume, like many others, has origins in niche areas, chance discoveries and fortuitous encounters. Its roots lie in two separate sets of joint research experiences coming together to form a shared interest for the four editors in what is a burgeoning and emergent field. That interest is in research that treats the by-products of an activity as data and of research interest in itself: paradata, marginalia and fieldnotes. Yet how did we get here?

Ros Edwards' interest in by-products was sparked by listening to survey methodologists who were co-members of the ESRC National Centre for Research Methods (NCRM), discussing the 'paradata' created by delivering surveys (for example Turner et al., 2014). Her colleagues' reference to the useful information that could be gained by analysis of keystrokes and other electronic aspects of computer-aided surveys, prompted Ros to realise that the notes scribbled by fieldworkers on the paper copies of Peter Townsend's old poverty survey booklets (from the 1967-68 Poverty in the $U K$ Study) that she had spotted stored in the basement of a data archive could also be considered useful paradata. Chatting about this material with Ann Phoenix, whose Novella narrative analysis project was attached to the NCRM, together they conceived a project that investigated the possibilities for analysing the interviewer notes. This was the start of a fascination 
with paradata and marginalia, and, together with other colleagues, conducting research that analysed these by-products as data (initially funded by NCRM and later by an additional grant from the ESRC).

For John Goodwin and Henrietta O'Connor interest in the 'by-products' of research was sparked by the rediscovery of interview schedules from a lost research project on the transitions from school to work in 1960s Leicester (see Goodwin and O'Connor, 2006, 2015a; O'Connor and Goodwin, 2010) and the detailed interviewer notes that accompanied them. Knowing little about the origins of the lost project, Goodwin and O'Connor had to visit relevant archives and reconstruct the project using any research materials, by-products and ephemera that they could find. However, while the rediscovered interview schedules contained important data, there was a realisation that all of these research by-products (letters, correspondence, notes, interviewer notes and so forth) were valuable data in and of themselves that could also be subject to sociological analysis in their own right (see O'Connor and Goodwin, 2010). This research led them, along with colleagues, to revisit a number of past studies (The Established and the Outsiders; Young Adults in the Labour Market; and The Changing Structure of Youth Labour Markets), long forgotten researchers (Pearl Jephcott) and the contributions of well-known sociologists (C. Wright Mills) using paradata, marginalia and fieldnotes as the subject and object of their analyses (for example, see Goodwin and O'Connor, 2015).

These two strands of work came together in 2012 when Henrietta made a chance discovery of an article in an NCRM newsletter in which Ann and Ros had asked the question 'what can we do with marginalia, notes and letters?' (see Phoenix et al., 2012). The question resonated and it was clear that all four editors were grappling with the same issues. After a brief exchange of correspondence at the end of 2012 (John with Ann and Henrietta with Ros) the idea for collaboration and a one-day conference gradually emerged.

A collaborative event focusing on working with microparadata and marginalia . . . Presentations could include our team on working with written microparadata in the late '60s Poverty in the UK booklets, our colleagues at Bristol . . on working with audio-recorded microparadata for the contemporary Poverty and Social Exclusion project ... and of course yourself and John Goodwin on your work with Elias's early 1960s study and/or the analysis of the '80s material.

(Ros Edwards to Henrietta O'Connor, June 2013)

The conference - Working with Paradata, Marginalia and Fieldnotes: The Centrality of By-Products of Social Research - was held at the University of Leicester in January 2014 and was jointly organised by the NCRM and 
members of the Department of Sociology at the University of Leicester. The key issue addressed by speakers at the conference, in line with the central problem considered in the chapters of this book, was how do we as social scientists make the very best use of the 'by-products' of social research? Through the conference, we sought to bring together colleagues working in this area for a 'dialogue' across disciplines and research paradigms: across the social sciences and humanities, historical and contemporary data, primary and secondary sources, and quantitative and qualitative approaches. The intention was exploring, learning and sharing our research practices, as there are no established conventions for using such data. This dialogue, and the opportunities to share and exchange afforded by the one-day conference, we considered to be crucial given that it is only very recently that social science researchers have begun to recognise the value of such data. This recent turn contrasts directly with other disciplinary areas. For example, if we consider marginalia there has been a rich tradition in the arts and literary criticism of exploring the 'histories' of books, manuscripts and documents through the inscriptions, notes, augmentations and marginalia recorded within them. As Orgel (2015) suggests:

inscriptions were so ubiquitous and marginalia not unusual; it is a rare book that remained unmarked in some way, even if only by an owner's name.

(Orgel, 2015: 19)

This quotation, from Orgel's (2015) The Reader in the Book, is useful in that it not only neatly captures the prevalence of such marginalia in ancient manuscripts but also points to the potential analytical value that such inscriptions can have for contemporary understandings of those texts. Orgel's (2015) interest is the history of the book via an 'archaeology of the use of margins and other blank spaces, a sociology of reading and writing in relation to ownership' (Orgel, 2015: 2). Much can be revealed about the ownership of, and engagement with, texts via an analysis of what has been 'added to' those texts whether directly related to the substantive context of the book or otherwise. So how would the approach advocated by Orgel (2015), amongst others (see, for example, Sherman, 2008, and also this volume) translate for the social sciences? How could an analysis of marginalia, paradata and fieldnotes complement the 'standard' methodologies and data sources across the social sciences? It is the case that those engaged in creating and analysing large-scale survey data are increasingly turning their attention to paradata, the context in which questionnaires are completed and the observations made during interviews as well as those factors which impact upon the recruitment and retention 
of participants. Likewise, for those researchers undertaking secondary analysis of existing datasets, there is analytical value in examining paradata and marginalia in the form of fieldnotes, fieldworker comments in the 'margins' of interview schedules, as well as the ephemera created during the research process. This is especially important given their potential to cast light on those otherwise usually hidden aspects of research in the field. As such, and by organising the conference, we were signalling, and remain convinced, that a discussion relating to the systematic use of the by-products of social research, by researchers themselves, is long overdue.

\section{MOVING FORWARD: TOWARDS A TYPOLOGY OF SOCIAL RESEARCH 'BY-PRODUCTS'}

In recent years, two methodological innovations have led researchers to attend to features of their research beyond the data collected. On the one hand, rising costs and falling response rates have led survey researchers to find ever-more sophisticated ways of understanding and improving survey quality and costs. Couper (1998) coined the term 'paradata' to refer to the by-products of data collection in survey research at either macro (the whole survey) or micro (survey case) level. 'Paradata' analysis is becoming well established in the quantitative field. The main focus has been on automatically captured audit trails from computer keystrokes such as the order of completion and revisions of answers; use of the help window; call records; non-response; and measurement error. The term is expanding, however, to include the context in which questionnaires are completed; interviewer-generated observations about the process of data collection; as well as the neighbourhood, housing unit, interviewee and interview (Kreuter and Casas-Cordero, 2010). These paradata have been collected and analysed in various surveys, with a view to improving recruitment and retention in large-scale datasets. Nicolaas (2011) has identified the methodological benefits of 'paradata' as improved understanding of data collection processes and evaluation and monitoring, including quality control. On the other hand, many qualitative researchers now analyse fieldnotes in order to better understand how research accounts are coconstructed between researchers and participants, allowing psychosocial, interpretivist or interactionist insights into the identities of both research participants and interviewers. In parallel with the use of fieldnotes in qualitative research, paradata allow interrogation of the place of the researcher in the data-gathering process. Both paradata and fieldnotes are, therefore, simultaneously methodology and productive of substantive data. Questions of analytic approach to fieldnotes and paradata are 
currently receiving research attention (e.g. Bell et al., 2014; Hollway, 2015), but require further work.

However, amongst the key issues explored during the conference, and again reflected upon in this volume, were definitional issues around what is actually meant by paradata, marginalia and fieldnotes. At first sight, these may appear to be disparate and different 'types' of data, all of which may be defined differently by scholars from different traditions, depending upon their epistemological proclivities. For example, the term 'marginalia' was coined in 1832 by Samuel Taylor Coleridge (Jackson, 2001) to describe a practice that was already current since 1700, of reader alterations to books, including marginal notes, underlining, highlighting and dog-earing (Jackson, 2001). People would sometimes write in books for one another in ways that Anderson (2011: 46) suggests was 'a kind of slow-motion, longform Twitter, or a statusless, meaning-soaked Facebook, or an analog, object-based G-chat'. Many researchers report a plurality of reasons for the production of marginalia, including better comprehension of meanings, conversing with other potential readers and engagement with the text, often intertextually (Fajkovic and Björneborn, 2014; Jackson, 2001; Sherman, 2008; Wagstaff, 2012). As with fieldnotes, marginalia, because it 'is unguarded, meant only as an aide-memoire, . . . can accidentally reveal much about the person writing it' (Moran, 2011). In much the same way, it is clear that while paradata analyses and social survey research appear to give minimal place to the identities, creativity and agency of researchers, these are still a central part of the data collection process (Bell et al., 2014). Used in this way, as data to add meaning to the data collection process, the main characteristic that all these different types of data have in common is that they can all be considered 'by-products', accompaniments or augmentations to broader research processes. So by imagining these paradata, marginalia, fieldnotes as 'by-products' we can include the whole, and vast array, of materials created and co-created during the research process (such as notes, files, annotations, keystrokes, observations, letters and correspondence, diaries and even photographs). These materials have major analytical value and can potentially add considerable depth to our understanding of the research process.

In Table 1.1 we outline a typology of paradata, marginalia and fieldnotes, as by-products of the research process. The examples we provide are not exhaustive and are not mutually exclusive. For example, letters and correspondence can be both paradata in the sense that they are by-products of the research process with the potential to offer insights but they may also contain marginalia that is interesting analytically in its own right. They can also be differentiated, in some respects, by the 'level of observation'. Paradata may be 'macro' and created at the level of the research design, 
Table 1.1 A typology of 'by-products' of social research

\begin{tabular}{ll}
\hline By-Products & Examples \\
\hline $\begin{array}{l}\text { Paradata } \\
\text { (macro) }\end{array}$ & $\begin{array}{c}\text { Keystrokes, respondent details, 'contextual' data, access } \\
\text { information, duration of data collection, research instrument } \\
\text { properties, respondent refusals and non-responses (see }\end{array}$ \\
& $\begin{array}{l}\text { Figure 1.1) } \\
\text { (micro) }\end{array}$ \\
& $\begin{array}{c}\text { Letters, correspondence, photographs, images, notes, } \\
\text { observations, research ephemera (see Figures 1.2 and 1.3) }\end{array}$ \\
Fieldnotes & $\begin{array}{c}\text { Fieldnotes, interviewer notes, recorded observations, research } \\
\text { diaries (see Figure 1.3) }\end{array}$ \\
Marginalia & $\begin{array}{c}\text { Annotations and augmentations to research instruments, books, } \\
\text { book proofs, letters and correspondence (see Figures 1.4 } \\
\end{array}$ \\
& and 1.5) \\
\hline
\end{tabular}

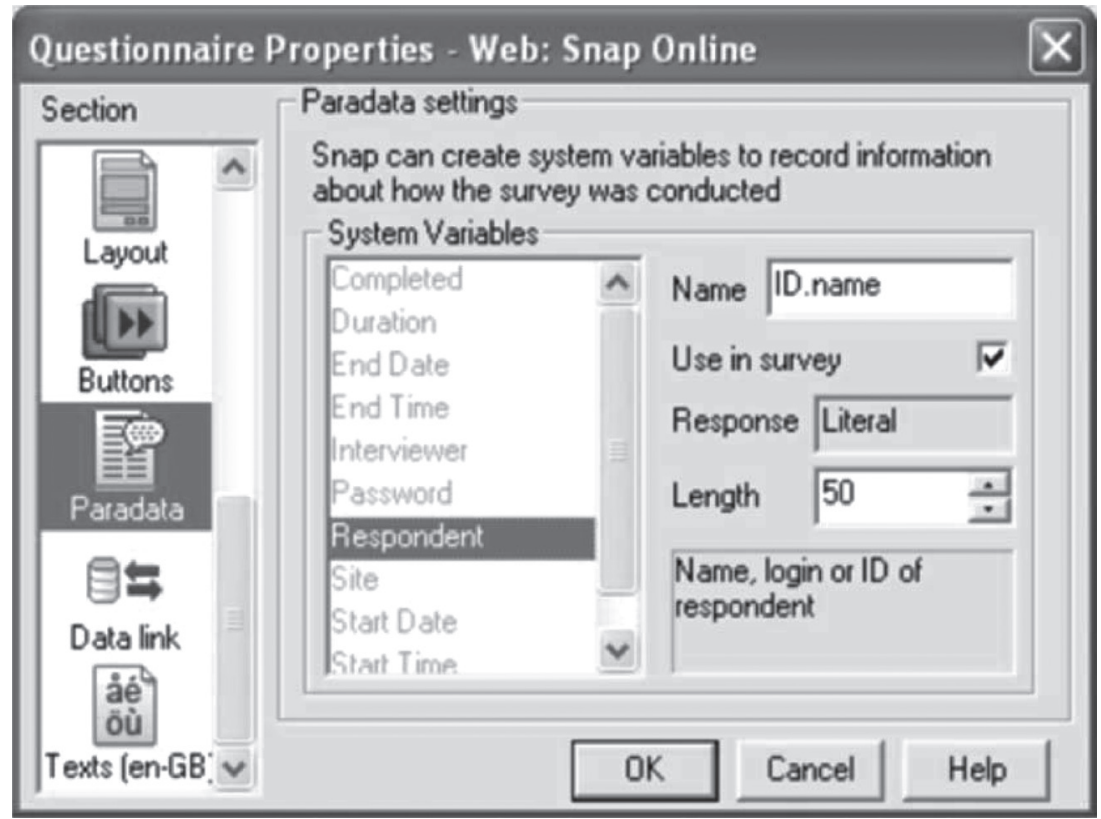

Figure 1.1 Paradata (macro) - screen shot of paradata creation software

research programme or research instruments or it could be more 'micro' and pertain to individual respondents or groups of respondents. Visual illustrations of the by-products of social research are provided and the first of these, Figure 1.1, is an example of macro paradata which shows the 


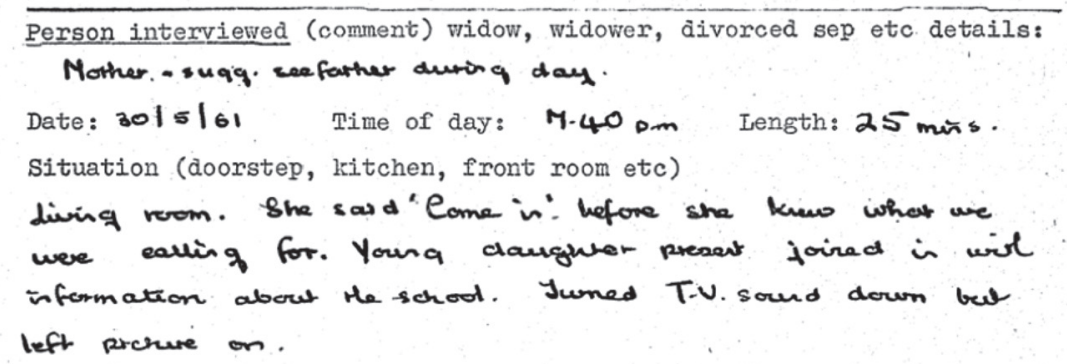

Source: From unpublished study by Dennis Marsden, ACE Parents and Education 19601961 [unprocessed study]. Colchester, Essex: UK Data Archive [distributor], SN: 6224.

\section{Figure 1.2 Paradata (micro) - survey fieldnotes}

detailed information collected when surveys are conducted. The menu on the left-hand side of the box includes a paradata icon revealing the extent to which this by-product of survey research has become integrated with the process of data collection.

Figure 1.2 is an example of micro paradata collected as part of an historical study on parental school choice. The interview schedule included questions designed to capture elements of micro paradata that may have impacted on the interview encounter, such as the date, time, length and location of the interview.

Figure 1.3 is an example of the interviewer notes section in Norbert Elias's Adjustment of Young Workers to Adult Roles project interview schedule. Here the interviewers were encouraged to record some of the factual information relating to the interview, as in Figure 1.2. From the figure we can see they also recorded their own reflections and impressions of the interview and any problems connected with work, family and leisure. The completed notes vary in length with some fieldworkers recording basic information whereas others recorded full and frank observations or detailed accounts of their impressions of the respondents and their surroundings.

Figure 1.4 is an example of more literary marginalia, a much more widespread, commonplace and familiar by-product; the notes made by readers in the margins of printed books. It illustrates clearly how marginalia is used to augment and add to existing texts to create additional meaning or note interpretations of the texts. Here we can see the author of the marginalia engaging directly with the author of the text, questioning and seeking a form of reflexive clarification of the actions, emotions and sentiments 


\section{INTERVIEWER'S NOTES.}

Please tick the appropriate descriptiop:-

83. Subject was friendly/indifferent (hostile.

84. Interview atmosphere was good/moderate/poor.

85. In your opinion, would respondent be willing to take part in further interviews? No $_{0}$

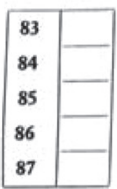

86. General impression from the interview, noting any problems connected with work,

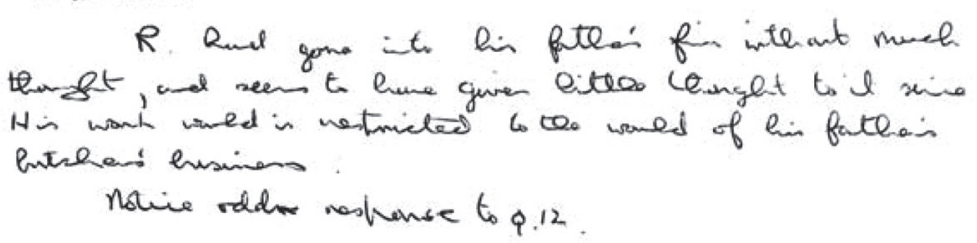

87. Any other comment.

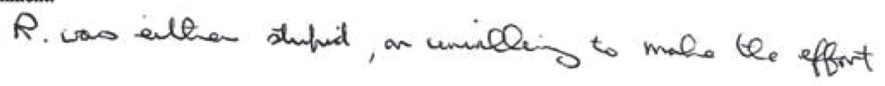

Figure 1.3 Fieldnotes - from adjustment of young workers to adult roles, 1962-1964

implied by the text. Such marginalia offer clear insight into the reader's interpretations.

Figure 1.5 is Pearl Jephcott's own proof copy of her book Time of One's Own (1967). Jephcott herself has annotated the front cover, made corrections, additions and alterations. In this sense marginalia may not only be about seeking clarification or documenting interpretation, but can also be revelatory regarding the writing process itself. It offers insight into how texts emerge, how writing and expression becomes refined or where the author has changed their mind. Such marginalia are instructive as they provide evidence that the writing process never ends but is a continually evolving practice. 


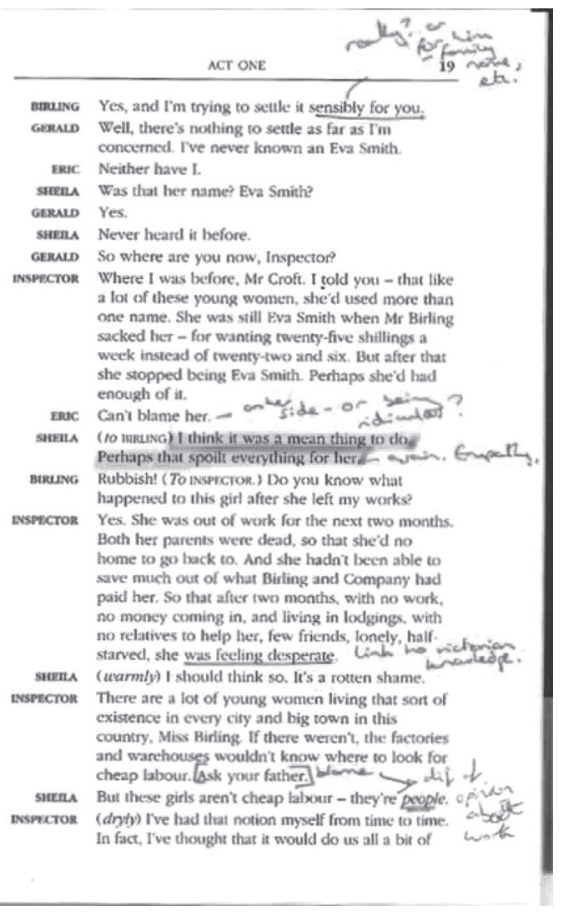

Figure 1.4 Marginalia-annotations, augmentations and additions (with thanks to Sarah Read)

\section{THE ANALYTIC POTENTIAL OF 'BY-PRODUCT' MATERIAL}

It would be remiss of us not to acknowledge those within the history of our disciplines who have actively encouraged the use of marginalia and paradata and who recognised, early on, the centrality of such material to the 'practice' of social science research. Most notable of these was the American sociologist C. Wright Mills. Mills was both an active creator of marginalia and paradata and a passionate advocate for the use of these 'by-products' in research practice as well as being one of the most innovative social scientists of the mid-twentieth century. The continual creation of marginalia was central to Mills's own sociological imagination. For example, in his letters and autobiographical writings Mills reveals something of how he developed his ideas and crafts his writings, outlining his working practices in To Tovarich: Specimen Days of My Life, Summer 1960. This was a letter to an 


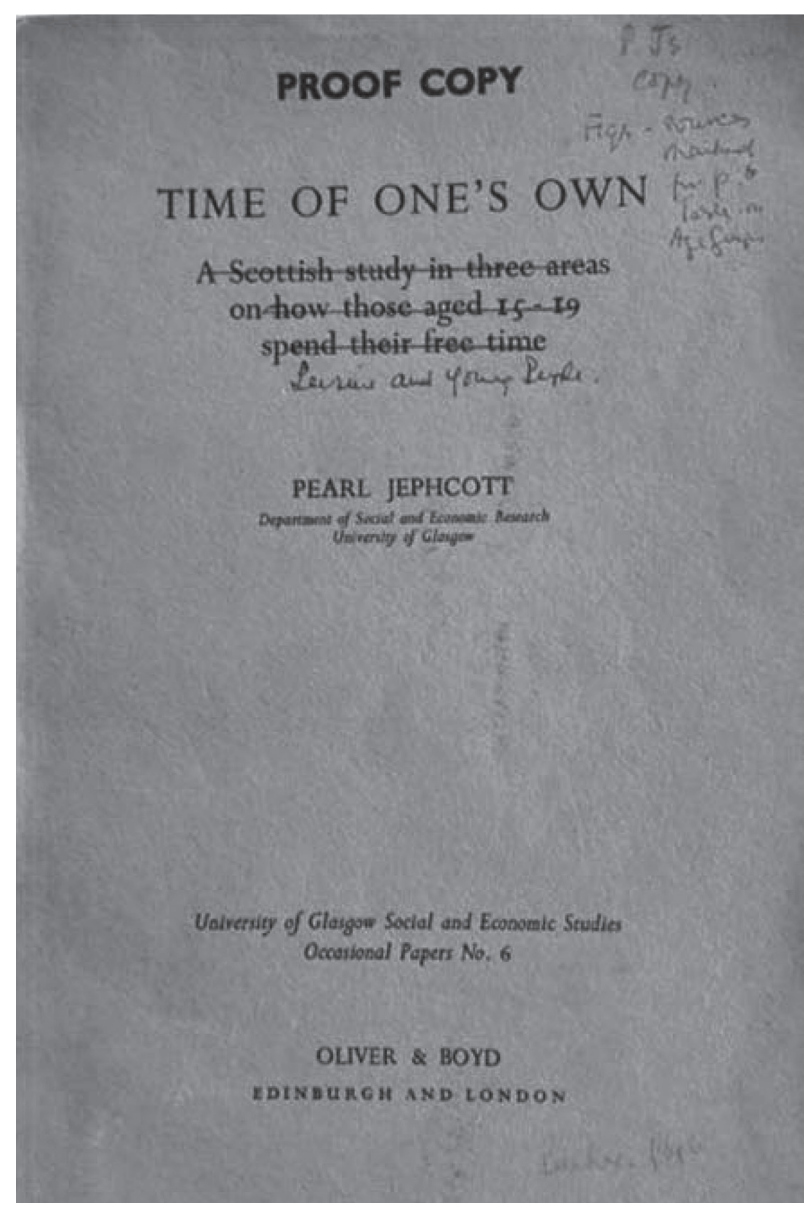

Source: Printed with permission of the estate of Pearl Jephcott.

\section{Figure 1.5 Marginalia-writing process and corrections}

imaginary Russian academic in which Mills sketches his working routines and how writing in the 'margins' was central to his creative process.

While the coffee is making, I go out to the road and get the New York Times. Then, with the paper and the coffee, I go up to my study ... Usually, it takes between twenty and forty minutes to read the paper, lying on the couch, marking it for clipping later. Sometimes I begin to write on the margins of the paper, spilling over onto one of the variously sized pads lying around.

(Mills, 1960 in Mills and Mills, 2000: 292) 
This approach is documented elsewhere and, in an interview for Pacifica Radio about Mills shortly after his death, the publisher Ian Ballantine points to the vast array of materials that Mills had assembled and the centrality of marginalia to Mills's sociological writing. Ballantine (1962) suggests that Mills:

had a Danish filing system in his den or office and everything in each drawer was all in good order. And there were several hundred drawers. He clipped a lot, relying heavily on the New York Times. He would write little remarks to himself in the margins of the story.

(Ballantine, 1962)

The remarks to himself in the margins, the constant 'clipping' of newspapers, books, magazines, articles, all retained in files in his Danish filing system, provided the stock of knowledge as well as the inspiration for Mills's own writing. In 2011, one of the editors of this volume (John Goodwin) visited the archived Mills papers housed at the University of Texas, Austin. From viewing the files, it is clear that Ballantine's observations were accurate - Mills carefully recorded and retained everything, keeping files of notes, clippings and various other research 'by-products' on every topic he encountered and became interested in. The files included full correspondence, notes, ephemera, pictures, letters, everything from a single word on a scrap of paper through to notations for lectures that Mills had given or was going to give. These marginalia, fieldnotes, paradata were central to his sociological practice and helped fuel his sociological imagination.

Mills also preaches what he practised himself and viewed the active creation of such materials as key to the research craft. He invites us to work as he worked, positioning paradata, marginalia, fieldnotes and the like as a very necessary part of developing and maintaining the 'sociological imagination'. For example, in the appendix to The Sociological Imagination (1959), titled On Intellectual Craftsmanship, Mills set out an agenda for sociological research practice designed to encourage the development of 'good habits' for research and the continual cultivation of ideas through systematic and repeated observing, recording and reflection. Mills encourages us to:

set up a file, which is, I suppose, a sociologist's way of saying: keep a journal. Many creative writers keep journals; the sociologist's need for systematic reflection demands it. In such a file as I am going to describe, there is the joined personal experience and professional activities, studies under way and studies planned. In this file, you, as an intellectual craftsman, will try to get together what you are doing intellectually and what you are experiencing as a 
person ... It also encourages you to capture 'fringe-thoughts': various ideas which may be by-products of everyday life, snatches of conversation overheard on the street, or, for that matter dreams.

(Mills, 1959: 196)

Here, Mills advocates the active creation of paradata, marginalia and fieldnotes and that such data should be placed in files. The process of creating a file and the constant reflection, re-ordering and mixing up of these materials, these by-products of everyday life, Mills suggests, are one way to 'invite imagination' (Mills, 1959: 212). This systematic process clearly worked for him.

Yet despite both the established tradition of literary and humanities scholars of using such materials, and the clear advice offered by Mills (1959) of using such materials for cultivating the sociological imagination, there remains no such established tradition (or even a consistent approach) within the social sciences for using the by-products of research. Nor has there been any sustained discussion as to the value of such 'additions' for social science research or how such materials could be used by social scientists. We can speculate as to why this may be and perhaps there are many reasons for this.

First, there is the dominance of a natural science view within the social sciences that primary data collection and analysis is the 'gold standard' approach to research. Why spend time examining the by-products of research when we should be concerned with more formal data types and collection methods? Why be concerned with what those working in the field recorded in their notes or focus on supplementary materials in relation to keystrokes, data entry, access to respondents or the research context more generally? As Hughes (2013) suggests, data such as this may suffer from dominant notions of empirical legitimacy and political alignment that impact on what we research, how we research it and which approaches and research areas are legitimised and privileged as compared to others.

Second, the privileging of types of data extends to data that are seen to be in the 'foreground' (the formal empirical data collected as part of the survey, interviews or observations directly from the field), as compared to data in the 'background' (paradata, marginalia, fieldnotes, photographs and ephemera) with the latter easily dismissed as merely 'context'. Do we need to analyse this contextual material when we cannot exhaust the analytic potential of this other, formally collected data? Why bother with contextual, background or supplementary materials? If we follow writers such as Elias, who advocated a 'holistic' approach to analysis, considering 'whole' processes or phenomenon (see, for example, Elias and Scotson, 1965; Goodwin and Hughes, 2011) then it becomes difficult, even arbi- 
trary, to make such an artificial distinction between data types and privilege one form of data (background, foreground, formal, informal and so forth) over another. We cannot use paradata, marginalia and fieldnotes as if they were somehow separate from, or incidental to, the more 'formal' data collection process. Paradata, marginalia and fieldnotes are data and are created as part of the data collection or analysis process. For example, one can only speculate as to what is in the research files, relating to issues of concern and projects underway, of those who adhered to the advice from Mills (1959). It is with some conjecture that we ask what paradata, marginalia and fieldnotes exist, perhaps stored away in attics, offices and archives. However, for those interested in the history of the social sciences, or in revisiting 'classic' research of the recent past (see Chapters 4, 5 and 6) then such paradata, marginalia and fieldnotes offer significant analytical value for a holistic understanding.

Third, and again a related point, a significant reason why paradata and fieldnotes may not be commonly used in the social sciences could be due to problems of access. One of the attractive features of marginalia is that they are available and can be found in books and written documents. Indeed, most public libraries have books on their shelves that someone at some point has thought fit to annotate, augment or even illustrate. However, the same may not be said for paradata and fieldnotes. While the formal data collected as part of a research project may be deposited in official archives, the paradata, marginalia and fieldnotes may not always accompany them, given the perceived secondary status and the personal nature of much of the by-products. Researchers may also retain their own research materials, given their personal investment in the research.

\section{OVERVIEW OF THE CHAPTERS}

As suggested above, the inspiration for this volume emerged from a oneday conference held at the University of Leicester in January 2014. The resultant volume is, we believe, rich in its interdisciplinarity. We have deliberately included contributions from a range of writers to enable us to highlight the importance of marginalia, paradata and fieldnotes in the arts, humanities and in the social sciences. The book is loosely structured into three sections. It begins with contributions from quantitative social science in the form of two chapters that explore the role of paradata in largescale contemporary survey-based research. The next section comprises three chapters each of which focus on more qualitative aspects of social research and each of which are concerned with reusing historical datasets primarily from the 1960 s but with a nod to the 1980s. All the authors of 
these three chapters were involved in the secondary analysis of large-scale sociological projects and had, independent of each other, become fascinated with the marginalia present in each of the studies and the richness that was added to the main data by notes that had previously been largely ignored. Finally, the last two chapters are from the humanities and explore the notion of marginalia that is perhaps best known - that of notes made by readers in the margins of books and manuscripts.

The collection begins then with two contributions which focus on the creation and use of numerically-based paradata in survey research. The first of these (Chapter 2), by Durrant and Maslovskaya explores the notion of paradata that is generated as a by-product of computer-assisted survey administration. Their interest is in investigations on nonresponse in social surveys that are administered face-to-face, via telephone or online and the insight that survey designers can gain from examining data on aspects such as call record data, interviewer observations and the length of question and answer sequences. Although initially this type of data was collected unintentionally it has become increasingly relevant in understanding aspects of survey administration such as non-response behaviours and thus feeds into the development of survey design. This, in turn can reduce costs and improve the quality of the data generated. Durrant and Maslovskaya use examples from their own research to demonstrate the use of paradata for interviewer-administered interviews. They end with practical suggestions for survey research design focused on understanding nonresponse through statistical modelling based on paradata, and working out which respondents to continue to follow up and when survey administrators should stop calling.

The third chapter is from Fahmy and Bell who provide an account of their use of paradata generated when collecting data for the UK Poverty and Social Exclusion Survey (2012 PSE-UK). The authors use their experience of collecting these recent data as a basis for identifying means of improving the quality of survey design. They argue that the use of paradata, in this case the analysis of actual interviewer and respondent interactions, can better improve survey design than the more traditional approach of survey pre-testing. Their interest lies specifically in the area of behaviour coding which is a technique used to identify issues affecting questionnaire administration that stem from the behaviours of the respondents and the fieldworker. Using an example from their own experience of collecting data for 2012 PSE-UK they show how paradata collected from interview transcripts can provide survey designers with valuable information enabling the identification of problems with questions and so helping to improve future survey design and enhance the quality of data collected in survey-based research. 
The next three contributions have a very different focus and take us in a slightly different direction. The authors of these three chapters have all revisited past empirical studies from the social sciences and use historical material to explore the importance of paradata, marginalia and fieldnotes. The first, written by Phoenix, Boddy, Edwards and Elliott, uses Townsend's renowned Poverty in the UK Study 1967/68 (PinUK). Rather than focusing on the extensive data collected by Townsend's team in the original survey research, Phoenix et al.'s attention became absorbed by the detailed handwritten notes they came across on the questionnaires themselves and it is this that they draw attention to here. The team used 69 annotated questionnaires from the original study and developed a typology of marginalia. This consisted of seven different categories that enabled them to analyse the comments made by the interviewers as amplifications, justifications and explanations of codes and evaluations of responses made by participants. The examples they draw upon in the chapter provide the reader with rich, descriptive accounts of the domestic lives of the respondents who took part in the study. Phoenix et al.'s account reveals much about the research process and the ways in which the researchers used marginalia as a way of making sense of research encounters. They also draw out the importance of marginalia as a means of adding depth and meaning to the quantitative nature of much of the coded data collected in the main survey.

Kilburn's chapter makes a different use of the same historical dataset, Townsend's Poverty in the UK Study, as used by Phoenix et al. in the previous chapter. He focuses on the housing conditions of interviewees and draws our attention to how informants' housing conditions were coded during survey interviews. In keeping with the Phoenix et al. chapter, Kilburn makes use of qualitative data that were not intended to be part of the main study. His interest arose from reading the marginalia and notes that fieldworkers made in spaces in the interview schedule, sometimes not more than a few words but in other cases filling a number of pages. Kilburn explores, in particular, responses and comments in the margin to the question of whether or not respondents believed they had a serious housing problem. Often responses to this question were contested - inhabitants did not consider that they had a housing problem, yet the marginalia reveal interviewers' accounts of very poor quality housing and overcrowding, making living circumstances intolerable. Thus, it was only through the marginalia that the true extent of poor housing conditions, central to the study, were revealed. Kilburn highlights here the insufficiency of coded, quantitative data made apparent by the interviewers' use of qualitative amplifications to the coded data in order fully to represent the housing conditions. 
The last of these three chapters is from O'Connor and Goodwin who use a range of by-products of social research, from a number of projects, to draw out the importance of focusing attention on material which is often not considered as data yet provides rich insight to the research process. Focusing on three different projects, the authors show that marginalia, fieldnotes and ephemera from historical social science research projects are of great value to the secondary analyst and help to shed light on research from the past. They begin by exploring fieldnotes from Norbert Elias's 1960 s project on youth employment. The marginalia and fieldnotes generated by the original research team have much in common with the data used by Phoenix et al. and Kilburn in the earlier two chapters. From extensive descriptive and very evocative fieldnotes they were able to gain insights into the lives of young people in Leicester in the 1960s - details that do not emerge from the more formal project data. Following on from this they turn to two other restudies on youth employment in the 1980s where again it is through additional notes in the margin and, as with Phoenix et al.'s and Kilburn's chapters, amplifications to the coded data, that the experience of school leavers in the 1980s really comes to life. Last but not least they turn to very different forms of research by-products and examine the importance of materials often stored in archives such as letters, photographs and research notebooks in providing invaluable additional, contextual information to the often over-sanitised published accounts of research projects. In this part of the chapter they explore letters written by the sociologist Norbert Elias to Ilya Neustadt, his Head of Department for the duration of the 1960s research project and to the notebooks and photographs of the sociologist Pearl Jephcott, a prolific researcher whose work is often forgotten by contemporary social scientists.

In the final two chapters of the book the focus shifts to the more traditional locus of marginalia - literary history. Jackson is a leading authority in the field and this chapter begins with a theme that is carried forward in Sherman's final chapter. Jackson explains how the custom of writing in books is frequently discountenanced and viewed as an act of defacing rather than enhancing a particular volume. However, the reader's attention is drawn to the fact that marginalia created by some individuals is actually highly valued and it is only the notes made by unknown readers that are frowned upon. By contrast marginalia created by famous historically significant individuals is highly prized in the literary world and adds value to the volumes where it is found. Using the example of marginalia created by John Adams (1735-1826), the second president of the USA, in three different publications, Jackson shows how Adams's extensive use of marginalia has provided future generations with a far greater understanding of his views and political outlook than 
would have been possible without these notes made in different volumes. An important point made by Jackson is that Adams's marginalia was not 'accidental' or intended simply as notes to himself. Books were rare and expensive during this period of history and were passed around a wide circle of potential readers. Therefore, notes made in the margin by readers such as Adams were not intended to be private - indeed there is much evidence that his extensive use of marginalia was an intentional action planned in part as a way of providing a 'public record of his life' for future generations.

The final chapter is a contribution from Sherman who is concerned primarily with readers' perceptions of marginalia and makes use of a wide range of fascinating and entertaining examples to take us through the literary history of marginalia. He draws our attention to a divide amongst readers, alluded to in the title: 'Soiled by use or enlivened by association' - between those who believe a book should never be blemished by marginalia, pen and pencil markings on the text to those who are happy to write in the margins of the volumes they read and will actively seek out and purchase copies of books that have been annotated and marked by earlier readers. Sherman explores this breach between readers using a wide range of fascinating examples of marked texts soiled by notes and marginalia, by evidence of frequent reading such as heavy thumbing of pages and perceptible food stains from readers who enjoyed books at mealtimes. He contrasts these 'messy' readers with those who have a preference for unsullied volumes. Virginia Woolf, for example, described the defacing of pristine pages as 'a sexual violation of both the text and its future readers' (Jackson, 2001: 239-40). Sherman ends his chapter by declaring his own preference for readers to continue the tradition of writing notes in the margins of books and to recognise the value of such markings to historians of the future. Thoughtfully he ends his chapter by leaving readers with a space in which to record their own marginalia!

Finally, a focus on the by-products of research and reading activities that brings together contemporary understandings of paradata, marginalia and fieldnotes, opens up an inter-paradigm and inter-disciplinary space. By-products are just as likely to consist of quantitative data, such as length of time, calculations about budgeting and so on, as they are of qualitative material, from a few short sentences to several pages. They are also just as likely to be found augmenting computer-assisted social surveys and ethnographic research as they are annotating a novel or music score. This boundary-crossing characteristic opens up the opportunity for drawing out an approach to understanding by-products that is inter-paradigmatic and inter-disciplinary. In rounding off the volume by highlighting the significance of bringing together these different disciplines and approaches, 
we lay the outlines of a new, relational approach to understanding and analysing paradata, marginalia and fieldnotes in our Afterword.

\section{REFERENCES}

Anderson, S. (2011) 'What I really want is someone rolling around in the text', The New York Times Magazine, 6 March, MM46. http://www.nytimes. com/2011/03/06/magazine/06Riff-t.html [Accessed 29 May 2016].

Ballantine, I. (1962) Contributor to: The causes of C. Wright Mills / Narrated by Elsa Knight Thompson and Saul Landau, Recorded on 7 September 1962. Los Angeles: Pacifica Radio Archive. http://pacificaradioarchives.org/recording/

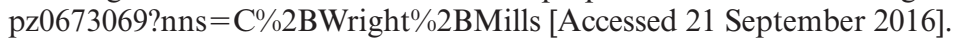

Bell, K., Fahmy, E. and Gordon, D. (2014) 'Quantitative conversations: the importance of developing rapport in standardised interviewing', Quality and Quantity, 50(1): 193-212.

Couper, M. (1998) 'Measuring survey quality in a CASIC environment', in Proceedings of the Section on Survey Research Methods of the American Statistical Association.

Elias, N. and Scotson, J. (1965) The Established and the Outsiders. London: Frank Cass.

Fajkovic, M. and Björneborn, L. (2014) 'Marginalia as message: affordances for reader-to-reader communication', Journal of Documentation, 70(5): 902-926.

Goodwin, J. and Hughes, J. (2011) 'Ilya Neustadt, Norbert Elias, and the development of sociology in Britain: formal and informal sources of historical data', British Journal of Sociology, 26(4): 677-695.

Goodwin, J. and O'Connor, H. (2006) 'Norbert Elias and the lost young worker project', Journal of Youth Studies, 9(2): 159-173.

Goodwin, J. and O'Connor, H. (2015) 'Pearl Jephcott: the legacy of a forgotten sociological research pioneer', Sociology, 49(1): 139-155.

Goodwin, J. and O'Connor, H. (2015a) Norbert Elias's Lost Research: Revisiting the Young Worker Project. Farnham: Ashgate.

Hollway, W. (2015) Knowing Mothers: Researching Maternal Identity Change. Basingstoke: Palgrave Macmillan.

Hughes, J. (2013) 'Norbert Elias and the habits of good sociology', Human Figurations, 2(1). http://quod.lib.umich.edu/h/humfig/11217607.0002.107/--norbert-elias-andthe-habits-of-good-sociology?rgn $=$ main; view $=$ fulltext $[$ Accessed 27 February 2016].

Jackson, H.J. (2001) Marginalia: Readers Writing in Books. New Haven and London: Yale University Press.

Jephcott, P. (1967) Time of One's Own. Glasgow: Oliver and Boyd.

Kreuter, F. and Casas-Cordero, C. (2010) 'Paradata', RatSWD Working Paper No. 136, German Council for Social and Economic Data.

Mills, C.W. (1959) The Sociological Imagination. New York: Oxford University Press.

Mills, C.W. (1960) 'To Tovarich: specimen days of my life, summer 1960', in Mills, K. and Mills, P. (2000) C. Wright Mills: Letters and Autobiographical Writings. Berkeley, CA: University of California Press, 292-304. 
Moran, J. (2011) 'Why I write in the margin', The Guardian, Comment is Free, 22 March. http://www.theguardian.com/commentisfree/2011/mar/22/notes-inthe-margin-social-networking [Accessed 29 May 2016].

Nicolaas, G. (2011) Survey Paradata: A Review. Discussion Paper. NCRM/017.

O'Connor, H. and Goodwin, J. (2010) 'Utilizing data from a lost sociological project: experiences, insights, promises', Qualitative Research, 10(3): 283-298.

Orgel, S. (2015) The Reader in the Book. Oxford: Oxford University Press.

Phoenix, A., Boddy, J., Elliott, H. and Edwards, R. (2012) 'What can we do with marginalia, notes and letters? The possibilities of narrative analysis for paradata in historical surveys', Methods News: The Newsletter from the ESRC National Centre for Research Methods, Winter 2012: 4.

Sherman, W. (2008) Used Books: Marking Readers in Renaissance England. Philadelphia: University of Pennsylvania Press.

Turner, G., Sturgis, P. and Martin, D. (2014) 'Can response latencies be used to detect survey satisficing on cognitively demanding questions?', Journal of Survey Statistics and Methodology. http://jssam.oxfordjournals.org/content/ early/2014/12/05/jssam.smu022 [Accessed 22 September 2016].

Wagstaff, K.L. (2012) The Evolution of Marginalia. http://www.wkiri.com/slis/ wagstaff-libr200-marginalia-1col.pdf [Accessed 8 November 2016]. 